\title{
Depression Differentially Predicts Quality of Life at levels of Self-Efficacy and Social Support in Cardiovascular Patients
}

\section{Shameem Fatima}

Department of Humanities, COMSATS Institute of Information Technology, Lahore, Pakistan

Corresponding Author: Shameem Fatima, Assistant professor Psychology, Department of Humanities, COMSATS Institute of Information Technology, Lahore, Pakistan. Email: shameem_pu@hotmail.com, shameemfatima@cuitlahore.edu.pk

Received Date: December 02, 2019; Accepted Date: January 11, 2020; Published Date; January $14,2020$.

Citation: Shameem Fatima, Depression Differentially Predicts Quality of Life at levels of Self-Efficacy and Social Support in Cardiovascular Patients. J. Psychology and Mental Health Care, 4 (1). Doi: 10.31579/2637-8892/063.

Copyright: (C) 2020 S. Shameem Fatima, This is an open-access article distributed under the terms of the Creative Commons Attribution License, which permits unrestricted use, distribution, and reproduction in any medium, provided the original author and source are credited.

\begin{abstract}
Objective: The objectives of the study were twofold: i) to assess whether depression independently predicts four quality of life (QOL) domains in CVD patients; and ii) whether depression interacts with self-efficacy and perceived social support to predict QOL domains among cardiovascular diseases (CVD) patients.

Methods: Participants were 174 CVD patients taken from three major government sector hospitals of Lahore who were assessed on self-report measures of depression, self-efficacy, social support and QOL.

Results: It was found that depression was a significant negative predictor of all four QOL domains among CVD patients. Furthermore, results from regression analysis demonstrated that depression significantly interacted with selfefficacy to predict physical and environmental QOL. Additionally, depression interacted with social support to physical and social QOL. Specially, depression was a stronger negative predictor of QOL domains at lower levels of self-efficacy and social support while it was a poor predictor at higher levels of self-efficacy and support.
\end{abstract}

Conclusion: It was concluded that social support and self-efficacy act as buffering factors against devastating effects of depression on QOL among CVD patients.

Since a few decades, Cardiovascular disease [CVD] has became a serious health issue which has been rising speedily around the globe and particularly in Asian-Pacific region (Gaziano, Reddy, Paccaud, Horton, \& Chaturvedi, 2006; Pillai \& Ganapathi, 2013). Being a significant cause of mortality, the illness has caused $29 \%$ worldwide deaths (World Health Organization [WHO], 2011), of which $80 \%$ deaths were from developing countries. Besides deaths, CVD may bring out many mental health symptoms such as anxiety, depression, and stress. The prevalence of anxiety and depression is four times higher in CVD patients compared to the normal population (Eisele et al., 2013). Depression and anxiety symptoms are reported as most frequently co-occurring mental disorder symptoms in the CVD patients living in both developed and developing countries (Kessler et al., 2005; Hu, Li, \& Arao, 2015). Earlier, such mental health symptoms and particularly depression were considered to be typical reactions to physical illness but recently, it has been illustrated that the occurrence of CVD has significant undesirable effects on overall health and QOL (Bhat \& Sahn, 2004), therefore, assessment and treatment of depression and related psychological symptoms in CVD patients requires special attention for their better QOL and psychological wellbeing (Williamson et al., 2000). Unfortunately, research is very rare in relation to depression and QOL in CVD patients, particularly from developing countries of Asian region (Piko, 2008; WHO, 2002). Therefore, to fill this research gap, the current study aims to assess whether depression directly predicts and interact with self-efficacy and social support to predict quality of life (QOL) domains among cardiovascular diseases (CVD) patients.

Earlier literature has shown that poor QOL is also a significant associates feature in CVD patients (e.g., Moser et al., 2010) and many studies have reported that the depression symptoms in CVD patients have been associated with poor QOL in CVD patients (Aggelopoulou et al., 2010). Quality of life is characterized by individuals' personal assessment of their life circumstances and situations particularly in relation to their prospects, aims, concerns, and beliefs. Moreover, this construct is a multidimensional construct comprising of physical, psychological, social, and environmental aspects. The physical aspect addresses daily routine life activities; the psychological dimension refers to feelings, spirituality, self-esteem, and personal beliefs; the social aspect covers social and personal relationships; and environmental aspect addresses financial resources, opportunities for recreation, and physical environment (Fleck et al., 2000).

With reference to the prevalence of depression symptoms, earlier findings have identified that $68 \%$ CVD patients report depressive symptoms according to the diagnostic criteria of DSM-IV (Dogar et al., 2008). Such a high prevalence of these mental disorder symptoms is a likely threat to QOL among CVD patients. A review study conducted with CVD patients has documented that nine out of 11 studies illustrated depression as a significant predictor of decreased QOL while controlling for other possible confounding variables (Dickens, Cherrington, \& McGowan, 2012). Another study showed that young adults with congenital heart diseases were at higher risk of compromised QOL (Rose et al., 2005). A recent study has also described depression and anxiety, in addition to many demographic and medical factors, to be the significant negative predictors of overall QOL (Wang, Chow, Thompson, Koh, \& Kowitlawakul, 2016).

Literature suggests that perceived QOL is also predicted by the psychosocial factors such as perceived social and emotional support and self-competent beliefs (e.g., Duenas, Ramirez, Arana, \& Failde, 2011). Among protective resources against psychological effects of physical 
illnesses, supportive social circles are described in literature to enhance patients' adaptation to chronic illnesses (Gallant, 2003; Reblin \& Uchino, 2008). Adequate social support from different sources has been widely considered to be related to psychological adjustment and QOL in cardiac patients (Lett et al., 2005; Molloy, Orth-Gomer, 2000).

Self-efficacy refers to a person's belief in his or her abilities to maintain some degree of control over his or her functioning and to meet situational demands (Bandura, 1997). A person's self-efficacy belief influences his or her health related behaviors as patients with a higher level of self-efficacy may probably involve in health promoting activities (Arnold et al., 2005; Bandura, 2004). With particular reference to CVD patients, it has been reported that self-efficacy is a positive predictor of QOL and psychological adjustment (e.g., Joekes, Van Elderern, \& Schreurs, 2007; Sarkar, Ali, \& Whooley, 2007).

It is important to note that people experiencing the same severity of CVD may differ in psychological and social resources. Social cognitive theory may likely justify how differences in social and psychological protective resources may lead to varied psychological consequences in patient with same severity level of a disease (Brawley, Rejeski, \& Lutes, 2000; Woodgate, Brawley, \& Shields, 2007). The theory describes that self-efficacy and social support may interact with risk factors to reduce their deteriorating effects. The interaction can be synergistic (Fatima, Sharif, \& Zimet, 2018) or compensatory (e.g., Hamilton, Warner, \& Schwarzer, 2017). In accordance with compensatory hypothesis, it is quite likely that self-efficacy may compensate the undesirable consequence of depression that is a quite common co-occurring symptom in cardiac patients. In light of the literature review, the study postulates two hypotheses: i) to assess whether depression predicts four QOL domains namely physical, psychological, social, and environmental QOL; ii) to assess whether self-efficacy and perceived social support moderate the association of depression with four QOL domains.

\section{Method}

\section{Participants}

The study recruited 174 CVD patients $($ men $=75 \%$, women $=$ $25 \%)$, ages between 22 to 60 years $(M=45.55, S D= \pm 15.33)$ from the cardiac units of three government sector hospitals in Lahore: Punjab Institute of cardiology, Jinnah Hospital, Mayo Hospital (35\%, 34\%, 31\% respectively). Lahore is the fifth largest city in South Asia and is a cosmopolitan city with a population of more than 10 million. As far as duration of their cardiovascular disease is concerned, $32 \%$ percent of the sample was diagnosed during last one month, $46 \%$ was diagnosed during last one year, and $22 \%$ was diagnosed during last five years. Majority of the CVD patients were married (84\%) and achieved low educational level $(M=4.8, S D= \pm 2.59)$.

\section{Instruments}

The medical records of the patients were reviewed to assess their clinical histories, date of first diagnosis, and duration of CVD treatment. Demographic information was obtained through a questionnaire assessing age, gender, education, marital status, and ethnicity.

Depression Symptoms were examined using the Urdu version of The Hospital Depression Anxiety Scale (Mumford, Tareen, Bajwa, Bhatti, \& Karim, 1991) comprising 14 items distributed into two scales: depression and anxiety. In the current study, depression was assessed using 7 items comprising the depression subscale. These items were scored on a 4 point response format yielding a potential composite depression score ranging from 0 to 21 with a higher score representing a higher level of depression symptoms. In the current study, a coefficient of internal reliability for depression was .68.
Self-Efficacy was assessed from the General Self-efficacy Scale (a 10 item scale) that was originally developed by Schwarzer and Jerusalem (1995). The Urdu translation of the scale (Tabassum, Rehman, Schwarzer, \& Jerusalem, 2003) of the scale was used with the current study sample considering their national language being Urdu. The respondents were required to respond on a 4 point response format ranging from 'not at all true' (1) to 'exactly true' (4) toall items. A composite selfefficacy score on the scale was obtained by adding responses to all ten items. The composite score, thus obtained, ranged from a minimum likely score of 10 to a maximum likely score of 40 , where a higher composite score represented a greater level of perceived self-efficacy. Cronbach's alpha of the scale in current study was very good (.98).

Perceived social support was assessed from the Multidimensional Scale of Perceived Social Support (Zimet, Dhalem, Zimet, \& Farley, 1988) that was a 12 item scale. The Urdu translation of the scale was used (Akhtar et al., 2010). The scale assesses social support from three sources: family, friends, and a significant other. The items were scored on a 7-point Likert scale that ranged from 'very strongly disagree' (1) to 'very strongly agree' (7). A composite score was obtained by adding scores on all 12 items. Potential range of the composite score could be from 12 to 84 , with a higher score showing a higher level of perceived social support. Internal reliability coefficient of the scale as obtained in the current study was very good (.90).

Quality of life of CVD patients was examined using Urdu version of The World Health Organization Quality of Life Assessment Instrument - short version (Khan, Akhter, Ayub, Alam, \& Laghari, 2003). It is a 26 items scale which assesses four QOL aspects namely physical, psychological, social, and environmental QOL in addition to 2 general statements assessing a general index of perceived QOL(item 1) and general health (item 2). The raw scores obtained for four QOL domains were converted into transformed scores to range between 4 and 20 with the higher scores representing greater perceived QOL in the particular domain. In the present study, the Alpha coefficients were $.88, .75, .73$, and .80 for physical, psychological, social, and environmental QOL domains respectively.

\section{Procedure}

First, approval from Departmental Research Review Committee, COMSATS, and Lahore was obtained. Then, heads of cardiac units were contacted and briefed about the nature of study. Afterwards, CVD patients were contacted and briefed about the study nature and purpose, and assured of the confidentiality of their information. After obtaining a formal informed consent from the participant, they were assessed on study measures. After collecting the data, they were cordially thanked for their cooperation.

\section{Data analysis and results}

The Statistical Package for Social Sciences, version 21 was used for data analyses. Descriptive statistics were calculated for demographic variables as well as for study variables including depression, Self-efficacy, social support, and quality of life domains in all current study sample of CVD patients. It was found that $13 \%$ of all CVD patients showed no depression symptoms, $31 \%$ showed borderline depression, and 56\% showed the higher levels of depression symptoms as per depression categories defined in Hospital Anxiety Depression scale: a score of 0-7 represents absence; 8-11 represents borderline, and 12-21represents high level of depression.

The, correlations of depression, self-efficacy, and social support were calculated with general health and general quality of life as assessed from first two items of WHOQOL as well as with four QOL domains. It was found that depression was negatively correlated with both the general 
QOL and general health as well as with four QOL domains. Further, selfefficacy was positively correlated with four QOL domains as well as with general QOL but not with general health. Moreover, social support also significantly and positively correlated with both the general QOL and general health as well as with four QOL domains (see Table 1).

\begin{tabular}{|l|c|c|c|c|c|c|c|c|c|}
\hline Measures & Depression & SE & SS & GQOL & GH & PH.QOL & PS.QOL & S. QOL & EN. QOL \\
\hline$\alpha$ & .68 & .98 & .90 & - & - & .88 & .75 & .73 & .80 \\
\hline M & 11.27 & 26.79 & 59.55 & 3.23 & 2.80 & 10.16 & 13.14 & 10.41 & 12.18 \\
\hline SD & 3.52 & 6.36 & 14.84 & 0.83 & 0.88 & 2.37 & 2.01 & 2.35 & 2.26 \\
\hline Depression & - & -.67 & -.37 & $-.35^{* *}$ & $-.27^{* *}$ & $-.52^{* *}$ & $-.57^{* *}$ & $-.45^{* *}$ & $-.35^{* *}$ \\
\hline SE & & - & .11 & $.16^{*}$ & .14 & $.18^{*}$ & $.30^{* *}$ & $.16^{*}$ & $.20^{* *}$ \\
\hline SS & & & - & $.49^{* *}$ & $.40^{* *}$ & $.41^{* *}$ & $.50^{* *}$ & $.49^{* *}$ & $.43^{* *}$ \\
\hline GQOL & & & & - & $.43^{* *}$ & $.31^{* *}$ & $.58^{* *}$ & $.38^{* *}$ & $.43^{* *}$ \\
\hline GH & & & & & - & $.37^{* *}$ & $.49^{* *}$ & $.32^{* *}$ & $.43^{* *}$ \\
\hline PH. QOL & & & & & & - & $.58^{* *}$ & $.69^{* *}$ & $.68^{* *}$ \\
\hline PS. QOL & & & & & & & - & $.47^{* *}$ & $.70^{* *}$ \\
\hline S. QOL & & & & & & & & - & $.57^{* *}$ \\
\hline EN.QOL & & & & & & & & & - \\
\hline
\end{tabular}

\section{Note. ${ }^{*} \mathrm{p}<.01, * * \mathrm{p}<.001 ; \mathrm{SE}=$ Self-efficacy; SS = Socila Support; GQOL = General Quality of Life; GH = General health; PH = Physical; PS = Psychological; S = social; EN = Environmental; QOL = Quality of Life}

Table 1: Means, Standard Deviations, Alpha Reliabilities, and Correlations between Study Variables

Finally, moderation analysis was carried out in SPSS using Process. Moderation in Process is calculated using model 1 which shows the significance of regression weights for independent and dependent variables as well as of interaction term. Additionally, the model 1 in process shows conditional effects of independent variable on dependent variable at different levels of the moderator. In the current study, depression was entered in the regression model as predictor, a QOL domain as a criterion and self-efficacy as the moderator variable. Four such models were run for four QOL domains using self-efficacy as a moderator. Regression weights for predictor, moderator, and interaction terms were noted. Additionally, if any of the interaction term turned out to be significant, then, conditional effects of predictor on criterion at three levels of moderator (strong, moderate, and weak) were also noted for clearer understanding of the moderation effect (see Table 2).

\begin{tabular}{|c|c|c|c|c|c|c|c|c|}
\hline Predictors & \multicolumn{2}{|c|}{ Physical QOL } & \multicolumn{2}{|c|}{ Psychological QOL } & \multicolumn{2}{|c|}{ Social QOL } & \multicolumn{2}{|c|}{ Environmental QOL } \\
\hline & Coeff. & SE & Coeff. & $\mathrm{SE}$ & Coeff. & SE & Coeff. & $\mathrm{SE}$ \\
\hline Depression & $-.76^{* * * *}$ & .15 & $-.52 * * *$ & .12 & $-.40^{*}$ & .15 & $-.55^{* * *}$ & .16 \\
\hline SE & $.23 * * *$ & .06 & .10 & .05 & .08 & .06 & $.15^{*}$ & .07 \\
\hline DepressionXSE & $.01 *$ & .005 & .01 & .004 & .01 & .00 & $.01 *$ & .005 \\
\hline $\mathrm{R}^{2}$ & \multicolumn{2}{|l|}{.34} & \multicolumn{2}{|l|}{.34} & \multicolumn{2}{|l|}{.23} & \multicolumn{2}{|l|}{.14} \\
\hline Model fit & \multicolumn{2}{|c|}{$\mathrm{F}(168,3)=28.67 * * *$} & \multicolumn{2}{|c|}{$\mathrm{F}(168,3)=29.26 * * *$} & \multicolumn{2}{|c|}{$\mathrm{F}(168,3)=17.01 * * *$} & \multicolumn{2}{|c|}{$\mathrm{F}(168,3)=9.39 * * *$} \\
\hline $\begin{array}{l}\text { Conditional } \\
\text { effects at levels } \\
\text { of self-efficacy }\end{array}$ & \multicolumn{2}{|c|}{$\begin{array}{l}20.51=-.53 * * *(.06) \\
26.87=-46 * *(06)\end{array}$} & - & & \multicolumn{2}{|c|}{ 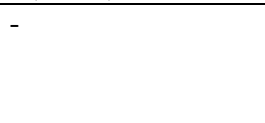 } & \multicolumn{2}{|c|}{$\begin{array}{l}20.51=-.30 * * *(.06) \\
26.87=-.23 * *(.06) \\
33.23=-.15(.07)\end{array}$} \\
\hline
\end{tabular}

Note. $* \mathrm{p}<.05, * * \mathrm{p}<.01, * * *<.001 ; \mathrm{SE}=$ Self-Efficacy

Table 2: Standardized Regression Weights Predicting Four QOL Domains from Depression as Moderated by Self-Efficacy in CVD Patients

Similarly, four moderation models were run using depression as a predictor, four QOL domains as a criterions and social support as the moderator variable. Regression weights for predictor, moderator, and interaction terms as well as conditional effects of predictor on criterion at three levels of moderator (strong, moderate, and weak) were also noted. The results are shown in Table 3.

\begin{tabular}{|l|l|l|l|l|l|l|l|l|}
\hline Predictors & \multicolumn{2}{|c|}{ Physical QOL } & \multicolumn{2}{c|}{ Psychological QOL } & \multicolumn{2}{c|}{ Social QOL } & \multicolumn{2}{c|}{ Environmental QOL } \\
\hline & Coeff. & SE & Coeff. & SE & Coeff. & SE & Coeff. & SE \\
\hline Depression & -.19 & .15 & $-.39 * * *$ & .14 & $-.58^{* *}$ & .17 & .06 & .19 \\
\hline SS & $.13 * * *$ & .04 & .02 & .02 & $.21 * * *$ & .03 & .09 & .04 \\
\hline DepressionXSS & $.01 * *$ & .003 & .002 & .001 & $.01 * * *$ & .002 & .003 & .002 \\
\hline $\mathrm{R}^{2}$ & .35 & .43 & & .40 & $\mathrm{~F}(168,3)=36.65 * * *$ & $\mathrm{~F}(168,3)=16.86 * * *$ \\
\hline Model fit & $\mathrm{F}(168,3)=30.57 * * *$ & $\mathrm{~F}(168,3)=41.64 * * *$ & $44.57=-.38^{* * *(.06)}$ & - \\
\hline $\begin{array}{l}\text { Conditional } \\
\text { effects at levels } \\
\text { of self-efficacy }\end{array}$ & $\begin{array}{l}44.57=-.40^{* * *}(.06) \\
59.27=-.28 * *(.04)\end{array}$ & - & & $\begin{array}{l}59.27=-.19 * * *(.04) \\
73.96=-.001(.06)\end{array}$ & \\
\hline
\end{tabular}




\section{Discussion}

The main objectives of the study were twofold: i) to examine whether depression independently predicts QOL domains among cardiovascular diseases (CVD) patients; and ii) whether depression interacts with self-efficacy and social support to predict QOL in CVD patients. The current study findings demonstrated that depression strongly and negatively predicted all four quality of life domains. Additionally, the result showed that depression is prevalent in the CVD sample; the finding is consistent with many studies reporting mental health symptoms of anxiety and depression in cardiac patients (e.g., Kessler et al., 2005; $\mathrm{Hu}$ et al., 2015). Additionally, depression significantly interacted with self-efficacy to predict physical and social QOL and interacted with social support to predict physical and environmental QOL. More specially, depression was more likely to be associated with poor QOL domains at lower levels of self-efficacy and social support while it was less likely to predict poor QOL at higher levels of self-efficacy and social support.

Following the primary objective, the study found that depression negatively predicted all four quality of life domains in CVD sample. The results supported our hypothesis and extended the generalization of previous findings based on diverse samples such as Western samples and samples of patients with diverse physical illnesses to the current sample of Asian CVD patient (e.g., Aggelopoulou et al., 2010), which have documented the adverse effects of depressive symptoms on QOL among patients with diverse medical conditions (e.g., pulmonary diseases and CVD). The negative prediction of QOL from depression is quite likely and justified in several ways. First, depression may lead to poor physical QOI in CVD patients may be because of physiologically mechanisms which may stimulate the sympathetic nervous system reducing optimal functioning of physical functioning. Second, CVD patients may behaviorally neglect their self-care and failing to follow the prescribed medications may also lead to poor physical QOL (e.g, Rozanski, Blumenthal, Davidson, Saab, \& Kubzansky, 2005). Additionally, the reciprocal links between negative emotions of depression and Psychological adjustment may justify poor psychological QOL. Finally, high level of depressive symptoms of being alone, sad, and low mood are more likely to be associated with poor social QOL.

The assessment of second objective showed that depression significantly interacted with self-efficacy to predict physical and social QOL and interacted with social support to predict physical and environmental QOL. Following self-efficacy as a moderator, it could be explained that depression was more likely to predict poor quality of life when the patient had poor self-efficacy and less likely to predict poor QOL if the patient had stronger self-efficacy. Self-efficacy itself was found to be a positive correlate of all four QOL domains and remained a positive predictor of physical and environmental QOL domains even after controlling the effect of depression. It means a higher level of selfefficacy buffer the adverse effects of illness related depression symptoms in decreasing patients QOL. The finding is supported from literature using a diverse range of samples both from developed and developing countries (e.g., Bandura, 2004; Fatima \& Jibeen, 2019). Specifically, self-efficacy had a buffering effect on physical and environmental QOL domains. Although depression is a negative factor that likely deteriorate QOL in CVD patients, its effect is still dependent and decreased if the patient had a positive resource factor of self-efficacy. The findings lend support to the compensatory hypothesis (Hamilton et al., 2017) that self-efficacy is likely to compensate the effects of depression. Additionally, the finding can be justified in that higher self-efficacy beliefs may enable CVD patients to compensate the undesirable consequences of depression by enabling them to perceive themselves as competent enough to improve QOL.

Following social support as a moderator, it was found that depression significantly interacted with social support to predict physical and environmental QOL. It could be explained that depression was more likely to predict poor quality of life when the patient had poor social support and less likely to predict poor QOL if the patient had higher levels of social support. Additionally, social support itself was a positive correlate of all four QOL domains and remained a positive predictor of physical and social QOL domains even after controlling the effect of depression. Consistent with the earlier findings (e.g., Fatima \& Jibeen, 2019; Reblin \& Uchino 2008), the current result suggests that higher levels of perceived social support from family, friends, and significant others improves QOL, particularly in CVD patients who need a lot of positive resources to fight the devastating effects of their physical illness. Many elucidations may likely justify social support to be a positive predictor of QOL. First, a CVD patient who has a supportive social circle probably be taken care of by the supportive members for adherence to healthy behaviors, compliance to medication, and meeting medical appointments, which in turn may promote physical QOL. Moreover, a sense of being supported may generate a feeling of self-worth and positive emotions which my probably reduce the negative effects of depression. The justification is supported by the stress buffering model which explains that social support may protect CVD patients from potentially devastating effects of stressful situation such as depression in patients of physical illnesses (Cohen \& Wills, 1985). Finally, social support may improve physical QOL by facilitating tangible support from supportive circle which in turn may facilitate access to medical and physical resources. Notably, the social support was a stronger correlate of stronger predictor of QOL domains compared to self-efficacy as is evident from correlation coefficients in Table 2 and comparative regression weights in Tables 2 and 3 .

\section{Implications and Limitations}

The present research will help cardiologists and general practitioners in understanding the risk of unidentified depressive symptoms and their effects on overall QOL of CVD patients. The strong correlations between depression symptoms and QOL domains highlight the need of proper screening and monitoring of these symptoms in CVD patients. Additionally, the results propose that cardiac rehabilitation centers should focus on designing intervention plans to improve selfefficacy and social relationships that may probably improve QOL. Earlier literature has supported that strategies aimed at improving social support and self-efficacy resulted in improved QOL and decreased physical and psychological co-occurring symptoms in patients with chronic illnesses (Hogan, Linden, \& Najarian, 2002; Rajati et al. 2014).

Some of the limitations of the study include absence of structured clinical (screening) interview based on the DSM-V criteria, and a lack of categorization of different CVDs. Therefore, studies with larger and variant sample characteristics from multiple sites examining patients in longitudinal studies are recommended. Moreover, cross sectional and correlational studies do not imply causal relationships; so, bidirectional relationships are recommended to be assessed in longitudinal research.

\section{Conclusion}

Depressive symptoms are highly prevalent co-occurring symptoms among CVD patients in Pakistan. However, supportive relationships and improved self-efficacy may compensate the deteriorative effects of depression on QOL.

\section{References}

1. Aggelopoulou, Z., Fotos, N. V., Chatziefstratiou, A. A., Giakoumidakis, K., Elefsiniotis, I., et al. (2017). The level of 
anxiety, depression and quality of life among patients with heart failure in Greece. Applied Nursing Research. 34, 52-56.

2. Akhtar, A., Rahman, A., Husain, M., Chaudhry, I. B., Duddu, V., Husain, N. (2010).

Multidimensional scale of perceived social support: psychometric properties in a South Asian population. Journal of Obstetrics and Gynaecology Research, 36(4), 845-51. doi: 10.1111/j.1447-0756.2010.01204.x.

3. Arnold, R., Ranchor, A. V., DeJongste, M. J., Koeter, G. H., Ten Hacken, N. H., et al. (2005). The relationship between selfefficacy and self-reported physical functioning in chronic obstructive pulmonary disease and chronic heart failure. Behavioral Medicine, 31, 107-115.

4. Bandura, A. (1997). Self-efficacy: The exercise of control. New York: Freeman.

5. Bandura, A. (2004). Health promotion by social cognitive means. Health Education and Behavior, 31, 143-164.

6. Bhat, A. H., \& Sahn, D. J. (2004). Congenital heart disease never goes away, even when it has been 'treated': the adult with congenital heart disease. Current Opinion in Pediatrics, 16, 500-507.

7. Brawley, L. R., Rejeski, W. J., \& Lutes, L. (2000). A groupmediated cognitive-behavioral intervention for increasing adherence to physical activity in older adults. Journal of Applied Biobehavioral Research, 5(1), 47-65.

8. Cohen, S. \& Wills, T. A. (1985). Stress, social support, and the buffering hypothesis. Psychological Bulletin, 98(2), 310-57.

9. Dickens. C., Cherrington, A., McGowan, L. (2012). Depression and health-related quality of life in people with coronary heart disease: a systematic review. European Journal Cardiovascular Nursing, 11(3), 265-275.

10. Dogar, I. A., Khawaja, I. S., Azeem, M. W., Awan, H., Ayub, A., et al. (2008). Prevalence and Risk Factors for Depression and Anxiety in Hospitalized Cardiac Patients in Pakistan. Psychiatry, 5(2), 38-41.

11. Duenas, M., Ramirez, C., Arana, R., \& Failde, I. (2011). Gender differences and determinants of health related quality of life in coronary patients: a follow-up study. Bio Med Central Journal of Cardiovascular Disorders, 11, 24.

12. Eisele, M., Blozik, E., Stork, S., Trader, J. M., HerrmannLingen, C., et al. (2013). Recognition of depression and anxiety and their association with quality of life, hospitalization and mortality in primary care patients with heart failure - study protocol of a longitudinal observation study. BMC Family Practice, 14, 180.

13. Fatima, S. \& Jibeen, T. (2019).Interplay of self-efficacy and social support in predicting quality of life in cardiovascular patients in Pakistan. Community Mental Health Journal, 55,855-864.

14. Fatima, S., Sharif, H., \& Zimet, G. (2018). Personal and Social Resources Interplay Synergistically to Enhance Academic Motivation. International Journal of Educational Psychology, 7((2), 196-226. doi: 10.17583/ijep.2018.3017

15. Fleck, M., Louzada, S., Xavier, M., Chachamovich, E., Vieira, G., Santos, L., \& Pinzon, V. (2000). Application of the Portuguese version of the abbreviated instrument of quality life WHOQOL- BREF. Revista de Saude Publica ,34, 178-183.

16. Gallant, M. P. (2003). The influence of social support on chronic illness self-management: A review and directions for research. Health, Education and Behavior, 30, 170-195.

17. Gaziano,T., Reddy, S., Paccaud, F., Horton,S., \& Chaturvedi, V. (2006). Disease control priorities in developing countries (2nd edition).
18. In Jamison, D.T., Breman, J.G., \& Measham, A.R, et al., editors. Washington (DC): World Bank.

19. Hamilton, K., Warner, L. M., \& Schwarzer, R. (2017). The Role of Self-Efficacy and Friend Support on Adolescent Vigorous Physical Activity. Health, Education, and Behvaior, 44(1), 175-181. doi: 10.1177/1090198116648266.

20. Hogan, B. E., Linden, W., \& Najarian, B. (2002). Social support interventions: do they work? Clinical Psychology Review, 22(3), 383-442.

21. Hu, H. H., Li,G., \& Arao, T. (2015). The association of family social support, depression, anxiety and self-efficacy with specific hypertension self-care behaviors in Chinese local community. Journal of Human Hypertension, 29, 198-203.

22. Joekes, K, J., Elderen, T.V., Schreurs, K. (2007). Self-efficacy and self-protection are related to quality of life, psychological well-being and self-management in cardiac patients. Journal of Health Psychology, 112(1), 4-16.

23. Kessler, R. C., Berglund, P., Demler, O., Jin, R., Merikangas, K. R., \& Walters, E. E. (2005). Lifetime prevalence and age-ofonset distributions of DSM-IV disorders in the National Comorbidity Survey Replication. Archives of General Psychiatry, 62, 593-602.

24. Khan, M. N., Akhter, M. S., Ayub, M., Alam, S., \& Laghari, N. U. (2003). Translation and validation of quality of life scale, the brief version. Journal of the College of Physicians and Surgeons-Pakistan, 13(2), 98-100.

25. Lett, H.S., Blumenthal, J.A., Babyak, M.A., Strauman, T.J., Robins, C., \& Sherwood, A. (2005). Social support and coronary heart disease: Epidemiologic evidence and implications for treatment. Psychosomatic Medicine, 67(6), 869-878.

26. Molloy, G. J., Perkins-Porras, L., Strike, P. C., \& Steptoe, A. (2008). Social networks and partner stress as predictors of adherence to medication, rehabilitation attendance, and quality of life following acute coronary syndrome. Health Psychology, 27(1), 52-58.

27. Mumford, D. B., Tareen, I. A., Bajwa, M. A., Bhatti, M. R., \& Karim, R. (1991). The translation and evaluation of an Urdu version of the Hospital Anxiety and Depression Scale. Acta Psychiatrica Scandinavica, 83(2), 81-85.

28. Moser, D. K., Dracup, K., Evangelista LS, Zambroski, C. H., Lennie, T. A., Cet al (2010). Comparison of prevalence of symptoms of depression, anxiety, and hostility in elderly patients with heart failure, myocardial infarction, and a coronary artery bypass graft. Heart and Lung: The Journal of Critical Care, 39(5), 378-385.

29. Piko, B. (2008). Cardiovascular disease epidemiology: A Journey from the past into the future.

30. Pillai, H, S., \& Ganapathi, S. (2013). Heart failure in South Asia. Current Cardiovascular Review, 9(2), 102-111.

31. Rajati, F., Sadeghi, M., Feizi, A., Sharifirad, G., Hasandokht, T., \& Mostafavi, F. M. (2014). Self-efficacy strategies to improve exercise in patients with heart failure: A systematic review. ARYA Atherosclerosis, 10(6), 319-333.

32. Reblin, M., \& Uchino, B.N. (2008). Social and emotional support and its implication for health. Current Opinion in Psychiatry, 21(2), 201-205.

33. Rose, M., Kohler, K., Kohler, F., Sawitzky, B., Fliege, H., \& Klapp, B. F. (2005). Determinants of the quality of life of patients with congenital heart disease. Quality of Life Research, $14,35-43$.

34. Rozanski, A., Blumenthal, J. A., Davidson, K. W., Saab, P. G., \& Kubzansky, L. (2005). The epidemiology, pathophysiology, 
and management of psychosocial risk factors in cardiac practice: the emerging field of behavioral cardiology. Journal of American College of Cardiology, 45(5), 637-651.

35. Sarkar, U., Ali, S., \& Whooley, M. A. (2007). Self-efficacy and health status in patients with coronary heart disease: Findings from the heart and soul study. Psychosomatic Medicine, 69, 306-312.

36. Schwarzer, R., \& Jerusalem, M. (1995). Generalized SelfEfficacy scale. In J. Weinman, S. Wright, \& M. Johnston, Measures in health psychology: A user's portfolio. Causal and control beliefs (pp. 35-37). Windsor, UK: NFER-NELSON.

37. Tabassum, U., Rehman, G., Schwarzer, R., \& Jerusalem, M. (2003). Urdu Adaptation of the General Self-Efficacy Scale.

38. Wang, W., Chow, A., Thompson, D., Koh, K., \& Kowitlawakul, Y. (2016). Predictors of health-related quality of life among patients with myocardial infarction. Western Journal of Nursing Research, 38(1), 43-56. doi: 10.1177/0193945914546201.

39. The World Health Organization (2002). Reducing risks, promoting healthy life. Geneva, World Health Report.

40. World Health Organization. (2011). Global atlas on cardiovascular disease prevention and control Policies, Strategies and Interventions, 1-164.

41. Woodgate, J., Brawley, L. R., \& Shields, C. A. (2007). Social support in Cardiac rehabilitation exercise maintenance: Associations with self-efficacy and health-related quality of life. Journal of Applied Social Psychology, 37(5), 1041-1059.

42. Zimet, G. D., Dahlem, N. W., Zimet, S. G., \& Farley, G. K. (1988). The multidimensional scale of perceived social support. Journal of Personality Assessment, 52 (1), 30-41.
This work is licensed under Creative Commons Attribution 4.0 License

To Submit Your Article Click Here: Submit Article

DOI: $10.31579 / 2637-8892 / 063$

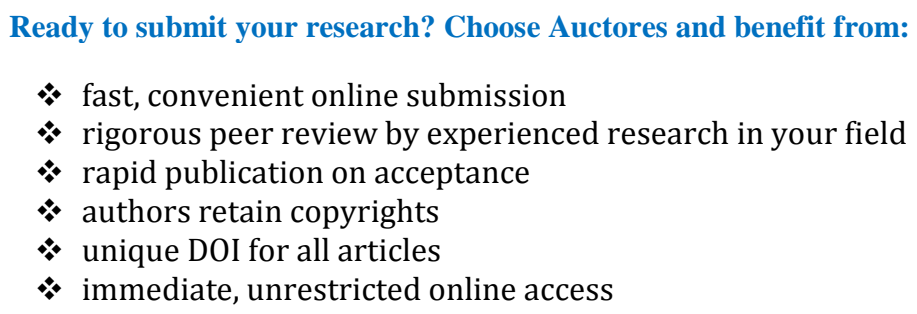

Ready to submit your research? Choose Auctores and benefit from:

* fast, convenient online submission

* rigorous peer review by experienced research in your field

* rapid publication on acceptance

* authors retain copyrights

* unique DOI for all articles

* immediate, unrestricted online access

At Auctores, research is always in progress.

Learn more www.auctoresonline.org/journals/psychology-and-mentalhealth-care 